\title{
Serious Complications After Epidural Catheter Placement: Two Case Reports
}

\author{
Ronald Seidel (1D) \\ Marc Tietke ${ }^{2}$ \\ Oliver Heese ${ }^{3}$ \\ Uwe Walter ${ }^{4}$ \\ 'Asklepios Medical Center, Department \\ of Anesthesiology and Intensive Care, \\ Schwedt, Germany; ${ }^{2}$ Helios Medical \\ Center, Department of Neuroradiology, \\ Schwerin, Germany; ${ }^{3}$ Helios Medical \\ Center, Department of Neurosurgery, \\ Schwerin, Germany; ${ }^{4}$ University Medical \\ Center Rostock, Department of \\ Neurology, Rostock, Germany
}

\begin{abstract}
Thoracic epidural analgesia (TEA) is a standard procedure in multimodal analgesia applied in major thoracic and abdominal surgeries. Two cases are presented with serious complications related to TEA. In both cases, earlier reaction of the treating physicians to patient-reported sensory symptoms could have prevented the complicated course. The first case was a 73-year-old patient with bronchial carcinoma who underwent right lower lobe resection. In this case, dabigatran $150 \mathrm{mg} / \mathrm{d}$ (indication: permanent atrial fibrillation) had been discontinued 72 hours before surgery, and enoxaparin $80 \mathrm{mg}$ (every 12 hours) had been started 11 hours after surgery. An epidural hematoma developed postoperatively. Magnetic resonance imaging (MRI) was performed only after paraplegia had developed the next day. Unfortunately, delayed hematoma evacuation could not prevent persistent paraplegia in this case, which was complicated by hospital-acquired pneumonia with sepsis and acute renal failure. The second case was a 39-year-old patient with ulcerative colitis and an initially undetected malposition of the epidural catheter. Immediately after test bolus injection, the patient reported paresthesia and overall discomfort, which however could not be safely attributed to either the test dose or the already started general anesthesia. The patient could only be extubated after stopping the epidural infusion. Accidental re-start of epidural infusion led to coma, conjugate eye deviation, and respiratory arrest, necessitating reintubation. Computed tomography (CT) ruled out intracerebral pathology and showed a catheter position centrally in the spinal canal. Fortunately, no neurological deficits were detected after catheter removal.
\end{abstract}

Keywords: epidural analgesia, dabigatran, paraplegia, perioperative complications

\section{Introduction}

Thoracic epidural analgesia (TEA) is a standard procedure in multimodal analgesia for major thoracic and abdominal surgery. A recent meta-analysis showed that epidural analgesia led to a significant reduction of mortality and serious cardiovascular and respiratory complications compared to opioid-based analgesia $(3.1 \%$ versus $4.9 \%$, respectively). However, epidural analgesia is associated with a significant increase of side effects such as urinary retention, pruritus, arterial hypotension and motor blockade. ${ }^{1}$ Therefore, the application of an epidural catheter in enhanced recovery after surgery concepts is critically debated and current recommendations favour the application of a local wound infiltration catheter, especially in laparoscopic interventions. ${ }^{2-4}$ Alternatively, thoracic or abdominal wall blocks can be performed. ${ }^{5,6}$ Serious complications after epidural catheterization are rare. However, the formation of an epidural hematoma or abscess, spinal infarction or mechanical complications with the catheter or needle typically result in paraplegia and can significantly impair the quality of life of affected patients. ${ }^{7-16}$
Correspondence: Ronald Seidel

Asklepios Medical Center, Department of Anesthesiology and Intensive Care, Am

Klinikum I, Schwedt, 16303, Germany

Tel +49333253452l

Email ronald-seidel@t-online.de 
Here, two critical incidents are presented with serious complications after epidural catheter placement, along with their implications for clinical practice. In both cases, written consent (case 1: authorized legal representative, case 2: patient) for publication of medical data and image material was provided. Institutional approval was not required to publish the case details.

\section{Case Presentation}

\section{Patient I}

We present the case of a 73-year-old male patient with a Body Mass Index (BMI) of 30.9 (weight $100 \mathrm{~kg}$, height $180 \mathrm{~cm}$ ) and American Society of Anesthesiologists Physical Status (ASA PS) of 4, in whom the following comorbidities were known: lung carcinoma of the right lower lobe (pT2pNOL0V1R0), chronic obstructive pulmonary disease, obstructive sleep apnoea syndrome, obesity, permanent atrial fibrillation, hypertensive heart disease, penis carcinoma, and history of cured colon carcinoma. The patient was readmitted to the hospital after preoperative preparation (laboratory workup, electrocardiogram (ECG), and chest X-ray) and having consented for surgery and anesthesia including epidural catheterization for postoperative pain control.

A right lower lobe resection and lymphadenectomy were performed. Dabigatran $150 \mathrm{mg}$ (indication: permanent atrial fibrillation) had been paused for 72 hours at this time (slightly restricted renal function: creatinine $95 \mu \mathrm{mol} / \mathrm{l}$, glomerular filtration rate [GFR] $68.2 \mathrm{~mL} / \mathrm{min}$ ). Two hours preoperatively the patient was given $1 \mathrm{~g}$ vancomycin intravenously because of known Methicillin-resistant Staphylococcus aureus colonization of the nasopharynx. After arrival in the operating theatre, we implemented a standard monitoring (ECG, pulse oximetry, and invasive blood pressure measurement via an arterial line in the left radial artery), inserted two peripheral venous accesses and connected a balanced electrolyte infusion (Jonosteril ${ }^{\circledR}$, Fresenius Kabi, Bad Homburg, Germany). A thoracic epidural catheter (EpiLong Tuohy $18 \mathrm{G}$ x 90mm, Pajunk, Geisingen, Germany) was placed in segment Th4/5 (sitting position, no supplemental medication, single median puncture attempt, loss of resistance to saline, no aspiration of blood or cerebrospinal fluid, free passive inflow of saline via the catheter, negative test dose: $15 \mathrm{mg}$ bupivacaine $0.5 \%$ ). The epidural space was reached at a depth of $6 \mathrm{~cm}$ and the catheter then advanced by $5 \mathrm{~cm}$. After induction of anesthesia (sufentanil/propofol/atracurium), a left-sided double-lumen endotracheal tube was placed (39F). The surgical intervention went without complications. The patient was treated postoperatively in the post-anesthesia care unit (PACU) and then transferred to the intermediate care ward (IMC). On the evening of the day of surgery, anticoagulation with enoxaparin $80 \mathrm{mg}$ (every 12 hours) was started subcutaneously.

On first postoperative day, the C-reactive protein (CRP) levels increased slightly (to $101.5 \mathrm{mg} / \mathrm{l}$ ). Renal function was almost unchanged (creatinine $113 \mu \mathrm{mol} / \mathrm{l}$, GFR $55.3 \mathrm{~mL} / \mathrm{min}$ ). In the evening of the first postoperative day, however, the patient described numbness in the left leg. This was attributed to epidural medication. MRI was not performed at this time.

On the second postoperative day CRP increased to $220 \mathrm{mg} / \mathrm{l}$. On suspicion of pneumonia, a calculated antibiotic therapy with linezolid $600 \mathrm{mg}$ (every 12 hours, duration: 7 days) and ceftriaxone $2 \mathrm{~g} / \mathrm{d}$ (duration: 4 days, then switch to ciprofloxacin $400 \mathrm{mg}$ [every 12 hours] for another 3 days) was started. The patient continued to require low doses of noradrenaline (maximum $0.08 \mu \mathrm{g} /$ $\mathrm{kg} / \mathrm{min}$ ). Kidney function continued to decline (creatinine $143 \mu \mathrm{mol} / 1$, GFR $41.6 \mathrm{~mL} / \mathrm{min}$ ), so that a sepsis with stage 1 acute kidney injury was diagnosed.

At this time, the patient complained of paraplegia in both legs, which persisted after stopping the epidural infusion (ropivacaine $0.2 \%$ with sufentanil $0.75 \mu \mathrm{g} / \mathrm{mL}: 8 \mathrm{~mL} /$ h). The MRI showed an epidural hematoma at the level of the thoracic vertebral bodies Th4 and Th5 (extension cranio-caudal: $33 \mathrm{~mm}$, extension antero-posterior: left side $10 \mathrm{~mm}$, right side $15 \mathrm{~mm}$ ) with compression of the myelon (Figure 1). Subsequently, $40 \mathrm{mg}$ dexamethasone were administered intravenously and laminectomy with removal of the epidural hematoma was performed.

The patient was extubated on the third postoperative day and transferred to a specialized rehabilitation center six days later. The spinal cord injury (level Th7, paraplegia of the legs) persisted unchanged (American Spinal Injury Association [ASIA] Grade A). The patient could be mobilized in a wheelchair and fed orally. In the meantime, a tracheotomy was performed due to recurrent respiratory insufficiency. Unfortunately, the patient died 4 weeks after the thoracic surgery from pulmonary embolism.

\section{Patient 2}

We present the case of a 39-year-old male patient with a BMI of 27.2 (weight $93 \mathrm{~kg}$, height $185 \mathrm{~cm}$ ) and an ASA PS score of 2. Due to an ulcerative colitis a laparoscopic 


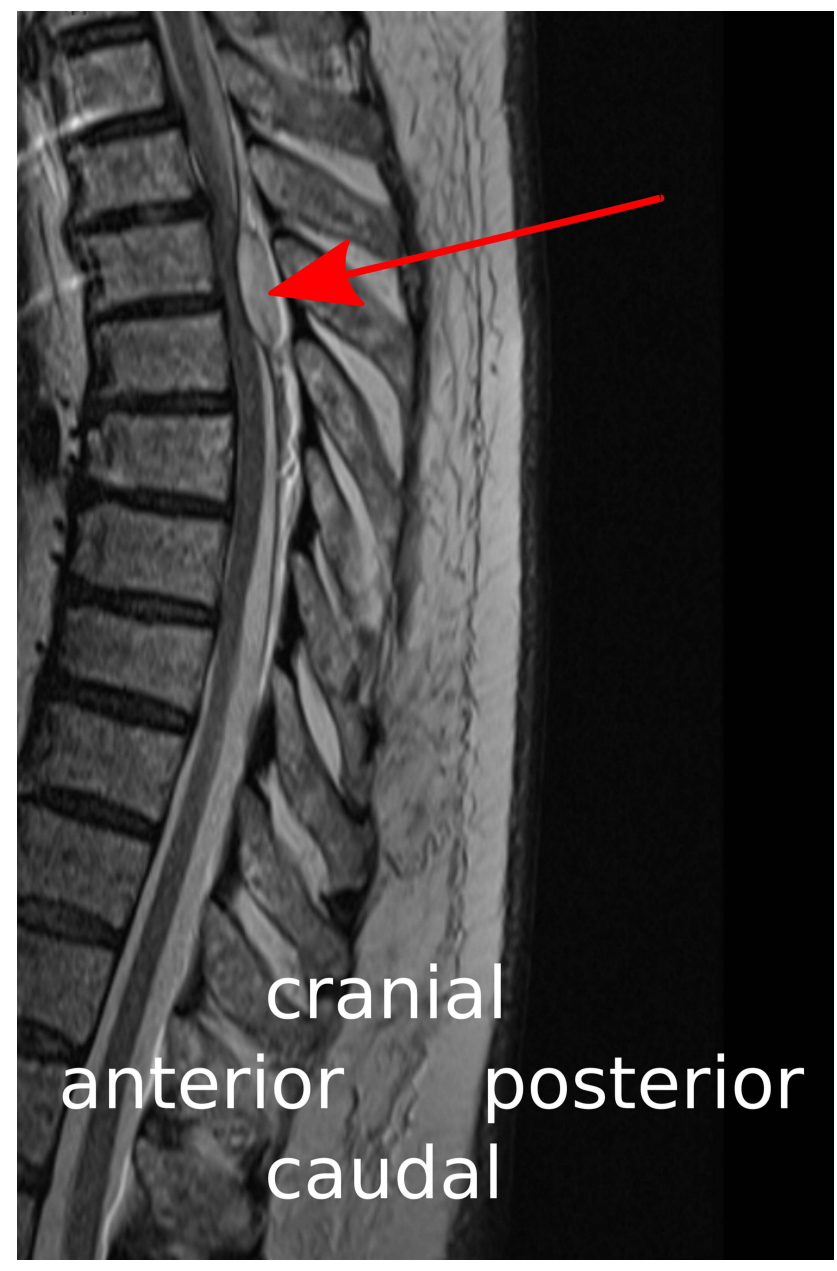

Figure I Midsagittal T2-weighted MR image showing the epidural hematoma (red arrow) with compression of the thoracic spinal cord at the level of the vertebral bodies Th4 and Th5.

proctocolectomy had been performed three months prior, including an uneventful epidural analgesia. The current hospital admission was necessary to perform an open residual coloproctomucosectomy including ileostomy (part two of a two-step ileo-anal-pouch procedure). Epidural catheterization was again planned for postoperative pain control. The patients medical history included allergic bronchial asthma, deep vein thrombosis (rivaroxaban $20 \mathrm{mg} / \mathrm{d}$ ), acute liver failure after moxifloxacin therapy, and septic complications (knee joint empyema, pneumonia, and acute kidney failure) as a result of immunosuppressive therapy (prednisolone and cyclosporine A).

The vital parameters were stable at the time of hospital admission with subjective well-being of the patient. In preparation for anesthesia we inserted two peripheral venous lines, administered a balanced electrolyte infusion $\left(\right.$ Jonosteril $\left.^{\circledR}\right)$ and implemented standard monitoring (ECG, pulse oximetry, noninvasive blood pressure measurement).

72 hours after the last dose of rivaroxaban, an epidural puncture was performed in a sitting position, without analgesic or sedative supplemental medication. The catheter (EpiLong Tuohy $18 \mathrm{G} \times 90 \mathrm{~mm}$ ) was successfully inserted (loss of resistance to saline technique) after repeated puncture attempts by a second experienced anesthetist at the level Th8-Th9. The puncture depth was $9 \mathrm{~cm}$, the catheter was advanced by $5 \mathrm{~cm}$ and fixed by a sterile dressing at $14 \mathrm{~cm}$ skin level. Up to this point no paresthesia occurred. The second anesthetist felt sure that the catheter was in the epidural space. As a result, the initial dose via the epidural catheter (bupivacaine $0.5 \%$ $20 \mathrm{mg}$ ) was administered almost simultaneously with the induction of anesthesia (propofol). Immediately thereafter the patient reported paresthesia and overall discomfort for the first time, which could not be safely attributed to either the epidural "test" dose or the induction of general anesthesia. The patient later described the symptoms as follows: feeling of warmth and tingling paresthesia on the right side, radiating from the ear, across the neck, the arm and reaching to the right groin.

The applied epidural medication in the perioperative period is summarized in Table 1 .

Intraoperatively the patient received only low doses of ephedrine (3 x $6 \mathrm{mg}$ ) and noradrenaline (maximum 0.04 $\mu \mathrm{g} / \mathrm{kg} / \mathrm{min}$ ). A total of $3500 \mathrm{~mL}$ balanced electrolyte solution (Jonosteril ${ }^{\circledR}$ ) was infused.

The patient did not wake up at the end of surgery (duration 205 minutes) and was ventilated for another 2 hours in the PACU. Extubation was achieved within 30 minutes after the "epidural" infusion has been stopped (90 minutes after end of surgery). He was somnolent (Glasgow Coma Scale [GCS] 14) but responsive at this time and

Table I Epidural Medication During the Perioperative Period

\begin{tabular}{|l|l|}
\hline $\begin{array}{l}\text { I. Before induction of } \\
\text { anesthesia }\end{array}$ & Bupivacaine $0.5 \% 4 \mathrm{~mL}$ \\
\hline 2. Before skin incision & Sufentanil $4 \mathrm{~mL}(20 \mu \mathrm{g})$ \\
\hline $\begin{array}{l}\text { 3. During surgery (205 } \\
\text { minutes) }\end{array}$ & $\begin{array}{l}\text { Ropivacaine } 0.2 \% \text { with sufentanil } 0.75 \\
\mu g / \mathrm{mL}: 8 \mathrm{~mL} / \mathrm{h} \text { (total volume } 2 \mathrm{I} \mathrm{mL})\end{array}$ \\
\hline $\begin{array}{l}\text { 4. In the Post-anesthesia } \\
\text { care unit ( } 90 \text { minutes) }\end{array}$ & $\begin{array}{l}\text { Ropivacaine } 0.2 \% \text { with sufentanil } 0.75 \\
\mu g / \mathrm{mL}: 8 \mathrm{~mL} / \mathrm{h} \text { (total volume } 12 \mathrm{~mL} \text { ) }\end{array}$ \\
\hline
\end{tabular}


moved all four limbs. The "epidural" infusion was restarted without consulting the responsible physician of the PACU, which within a few minutes led to coma (GCS 3), conjugate eye deviation to the right, and respiratory arrest. After re-intubation, a cerebral lesion (eg a basilar artery thrombosis) was suspected and, after intravenous application of an iodine-containing contrast medium (iomeprol), CT scans of the head and neck and of the thoracic spine were performed (Figures 2 and 3).

CT imaging showed catheter malposition (subdural, intrathecal or intramedullary). Unfortunately, the CT scan did not show the distal $4 \mathrm{~cm}$ of the catheter. The catheter

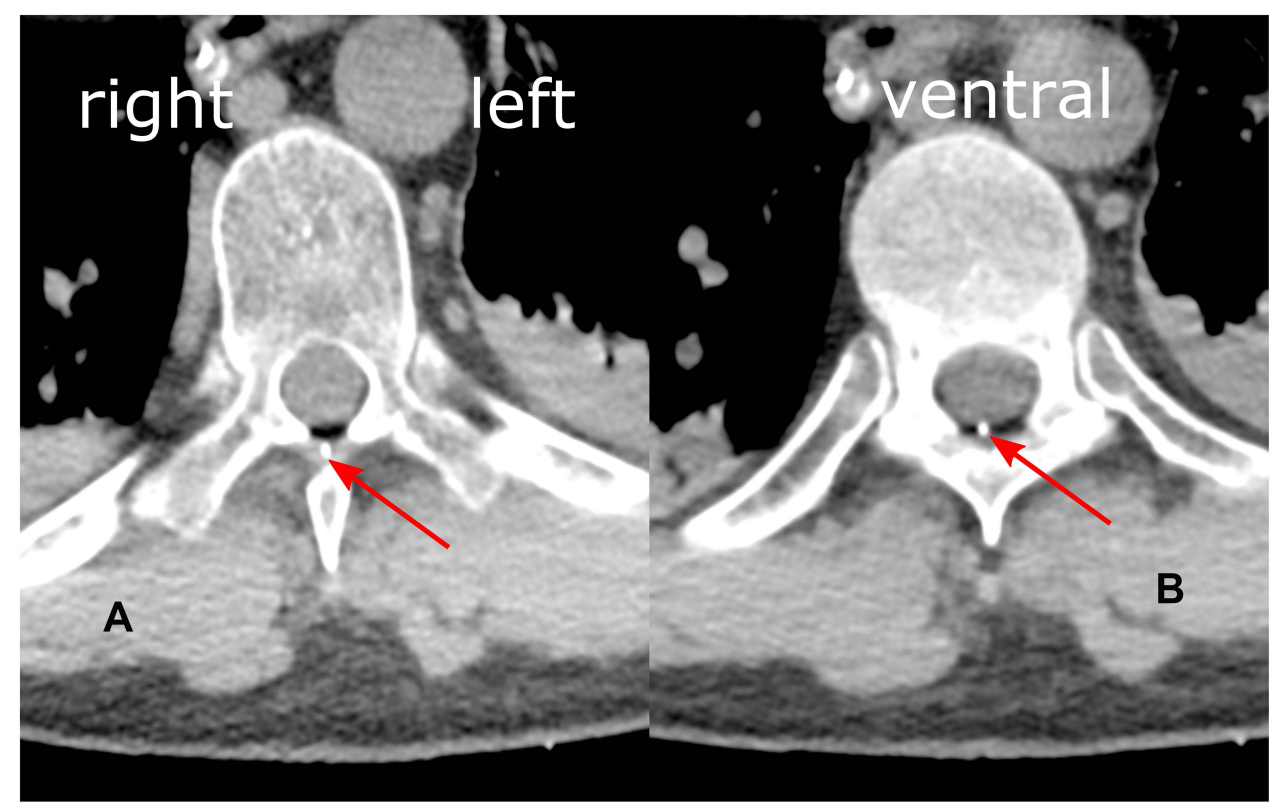

C

D

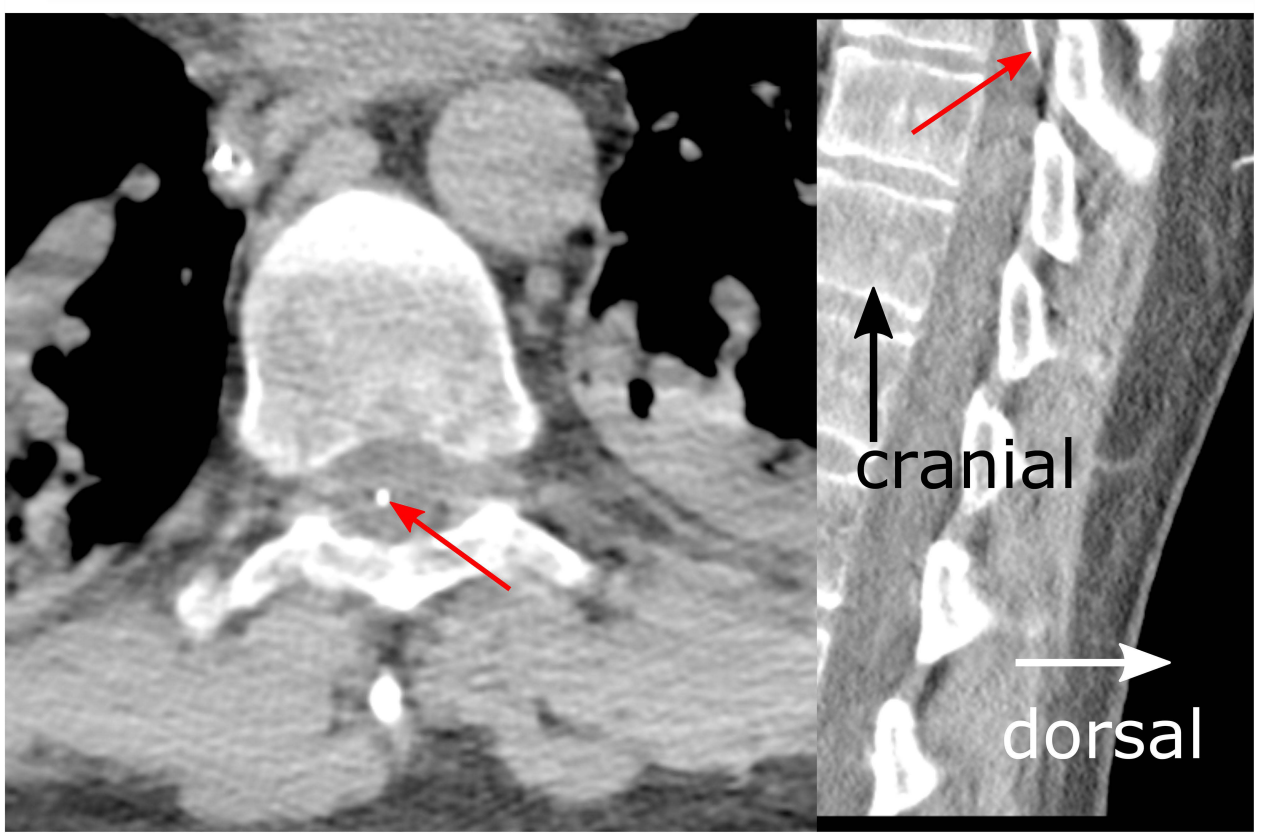

Figure 2 Detail enlargements of axial (A-C) and sagittal (D) thoracic CT scans in a soft tissue window at level Th9. Red arrows indicate epidural catheter (white dot). (A) (left upper panel): The catheter is shown passing the ligamentum flavum ventral to the spinous process. (B) (right upper panel): Imaging of the catheter in the epidural space. (C) (left lower panel): Catheter position almost in the middle of the dural sac, suggesting a position inside the spinal cord. (D) (right lower panel): Entry of the epidural catheter into the dural sac. The terminal 4 centimeters of the catheter are not shown. Additional findings: consolidations (atelectasis) of the posterior lower lobes, nasogastric tube. 


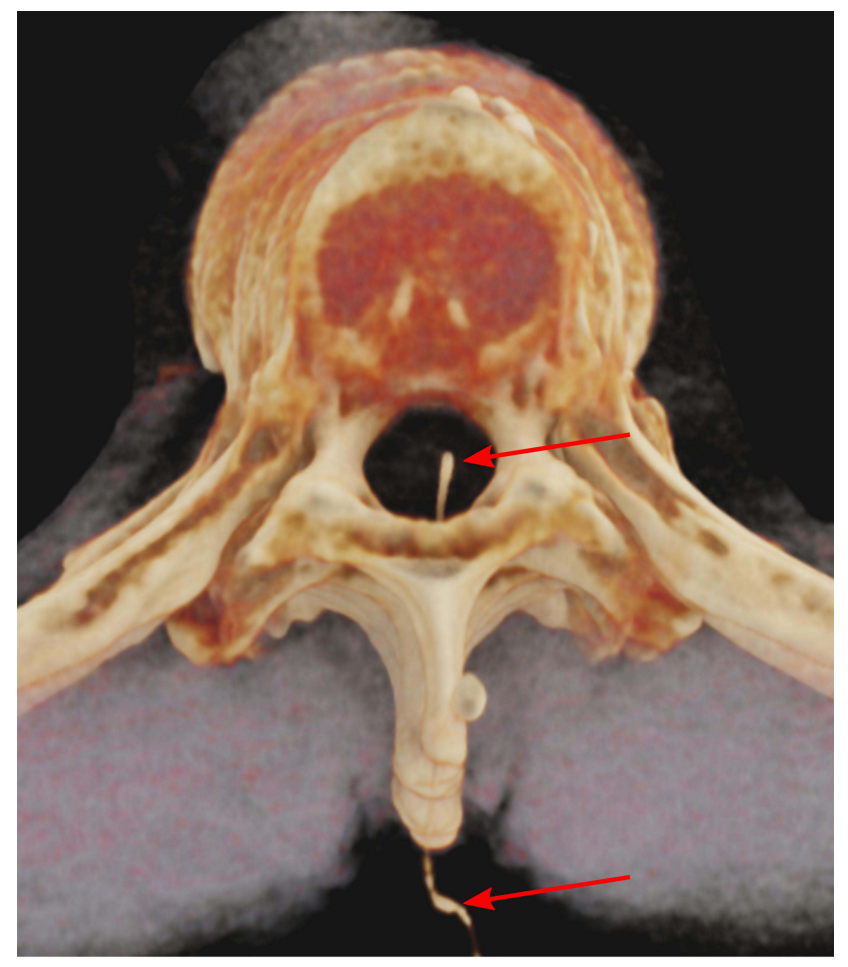

\section{left dorsal right}

Figure 3 Shaded surface display volume rendering (SS-VRT) of the thoracic vertebral column in head-feet-orientation: central, slightly right paramedian, position of the catheter inside the spinal canal. Red arrows indicate catheter.

was removed and the patient was transferred to the intensive care unit. Extubation was successful the following day. No neurological deficit was found and there was no post-dural puncture headache.

On the fifth postoperative day, a re-laparotomy with lavage and insertion of a drain was performed due to fibrinous peritonitis. The patient was discharged home without neurological deficits on the fifteenth postoperative day. MRI of the thoracic spine 9 months later showed no pathological findings.

\section{Discussion}

\section{Patient I}

Epidural catheter placement was successful in the first puncture attempt. No bloody puncture was observed. Dabigatran $150 \mathrm{mg}$ had been stopped 72 hours preoperatively, which is sufficient according to current guidelines. ${ }^{17}$ According to the ASRA recommendations the 12- to 17-hour half-life of dabigatran in healthy patients suggests a time interval of 34 hours ( 2 half- lives) between the last prophylactic dose $(\leq 220 \mathrm{mg} / \mathrm{d}$ dabigatran) and the subsequent neuraxial puncture/catheter removal. This time interval should be extended up to 85 hours (5 half-lives) when higher doses are used (>220 mg/ d dabigatran) or in patients with a creatinine clearance below $50(30-49) \mathrm{mL} / \mathrm{min}^{17}$

The first enoxaparin dose (plus mechanical prophylaxis of venous thromboembolism) was administered 11 hours after the epidural catheter was inserted. Here, too, the ASRA recommendation (12 hours) was approximately followed. The clinical effect of enoxaparin was not monitored by anti-Xa activity, which might have indicated a relative enoxaparin overdose due to acute renal failure.

The crucial factor in this case was the delayed diagnosis (MRI) and therapy (laminectomy) of epidural hematoma, 19 hours after the first clinical symptoms appeared. Thus, Vandermeulen et al demonstrated that the neurologic outcome in patients with spinal hematoma following neuraxial blockade depends on the interval between onset of paraplegia and surgical decompression. ${ }^{18}$

Nevertheless, it can be discussed whether the use of unfractionated heparin (eg $2 \times 7500 \mathrm{U}$ subcutaneously) and alternative oral anticoagulants (eg apixaban), both less affected by renal impairment, does not offer greater safety due to the lower risk of accumulation in situations where an epidural catheter is being considered.

A low puncture level (with extension of local anesthetic to the lumbar segments) and a high concentration of infused local anesthetic (promotes motor block) makes it more difficult to differentiate the cause of neurological deficits. Therefore, epidural infusion should be opioidbased (sufentanil $<1 \mu \mathrm{g} / \mathrm{mL}$ to avoid relevant systemic absorption) and contain only low (ropivacaine $\leq 0.2 \%$ ) concentrations of local anesthetic for sympathicolysis.

\section{Patient 2}

An epidural test dose (local anesthetic, epinephrine) is a widely used method to detect epidural catheter misplacements. Joanne Guay indicated that sensitivity and positive predictive values of $\geq 80 \%$, each demonstrated by at least two randomized controlled trials, are recommended for a test dose. ${ }^{19}$ These thresholds have been determined for intravascular catheter misplacements in distinct patient populations: nonpregnant adult patients (increase in systolic blood pressure $\geq 15 \mathrm{mmHg}$ or heart rate $\geq 10 \mathrm{bpm}$ after injection of 10-15 $\mu \mathrm{g}$ epinephrine), pregnant patients (sedation, drowsiness or dizziness within 5 minutes after $100 \mu \mathrm{g}$ of fentanyl), and children (increase in systolic 
blood pressure $\geq 15 \mathrm{mmHg}$ after injection of $0.5 \mu \mathrm{g} / \mathrm{kg}$ epinephrine). ${ }^{19}$

Balki et al compared epidural electrical stimulation (EEST) and local anesthetic test dose (LATD) for thoracic epidural catheters in abdominal surgery. To predict adequate postoperative epidural analgesia, the sensitivity (95\% confidence interval in square brackets) was higher for ESST (1 [0.93-1]) compared to LATD (0.79 [0.650.89]). Positive predictive values were comparable for ESST (0.84 [0.75-0.93]) and LATD (0.82 [0.710.92]). ${ }^{20,21}$ However, there is no test to detect intrathecal or subdural catheter misplacement with sufficient sensitivity. ${ }^{19}$

The epidural test dose in the authors hospital is administered as two to three repeated doses of $1 \mathrm{~mL}$ bupivacaine $0.5 \%$ after loss of resistance to saline, negative aspiration test (blood or cerebrospinal fluid) and passive fluid (saline 0.9\%) inflow (catheter end elevated at least $10 \mathrm{~cm}$ above the puncture level). In the absence of passive fluid inflow, the catheter is flushed with $1 \mathrm{~mL}$ saline, possibly retracted by $1 \mathrm{~cm}$ (initial advance $3-5 \mathrm{~cm}$ into the epidural space) and the inflow test repeated. The test dose is part of the initial bolus consisting of $4-5 \mathrm{~mL}$ bupivacaine $0.5 \%$ and $4-5 \mathrm{~mL}$ sufentanil $(20-25 \mu \mathrm{g})$. This standard operating procedure (SOP) was not followed in this case. Possible results of clinical tests depending on the catheter position are shown in Table 2. The local anesthetic test dose should not be applied until the clinical tests listed in Table 2 indicate an epidural catheter position.

An important issue is the existence of ligamentum flavum midline gaps (peak incidence Th10-Th12, incidence at level Th8/9: 4.4\%), because they can influence the loss of resistance to saline technique, especially with median punctures. ${ }^{22}$

Furthermore, it had clearly been demonstrated that a catheter cannot penetrate an intact dura mater. ${ }^{23}$ However, the needle may partly pierce the dura mater so that a catheter can either reach the subdural space (subdural block) or tear the subarachnoid membrane (spinal block). ${ }^{19,23}$ Typical symptoms of a subdural block are: delayed onset of symptoms (up to 30 minutes), mild hypotension, motor block not mandatory, no cerebrospinal fluid (CSF) aspirable, sensory block level much higher than expected from local anesthetic dose. ${ }^{24}$ Cases of rapid onset with loss of consciousness, respiratory arrest and deep hypotension are reported. ${ }^{25}$
The authors are not in complete agreement regarding the catheter position in this case. The evaluation is made more difficult because the cranial $4 \mathrm{~cm}$ of the catheter were not visualized in the initial CT. The almost central position (paramedian, right side) in the spinal canal suggests intramedullary misplacement of the catheter tip (Figures 2 and 3). Slavin presented a case in which, after implantation of an intrathecal catheter for continuous morphine infusion under general anesthesia, the symptoms were initially mild (catheter tip in the left anterior quadrant of the spinal cord; monoparesis of the right foot), so that the patient was first discharged home, where a progressive right-sided monoparesis of the leg developed during the following week. ${ }^{26}$ The intramedullary catheter position (entry in the myelon at Th11/12 level, catheter tip at Th7 level) was proven here with MRI and CT myelogram. Once the catheter was removed, the neurologic deficits gradually resolved.

However, clinical symptoms with lack of motor block, mild hypotension, loss of consciousness, respiratory arrest and missing aspiration of CSF could be more likely to indicate a subdural block.

This is also indicated by the absence of pathological findings in the MRI 9 months after catheter misplacement. A reliable differentiation between myelon and cerebrospinal fluid could only have been proven with MRI or CT myelogram.

What can we learn from this case? A local anesthetic test dose should be titrated with incremental doses over a prolonged period of time in the awake patient and in an environment with readily available emergency equipment. Alternative methods that support needle guidance and catheterization (electrical epidural stimulation, fluoroscopy, ultrasound-guidance and epidural waveform analysis) have not been widely used, but should be considered..$^{20,21}$

A major failure in this case was the unstructured and insufficient handover of the patient in the PACU, ignoring the hospital's SOP and leading to unnoticed restart of the "epidural" infusion. Various professional societies recommend implementation and training of the so-called SBAR concept ("S": situation, "B": background, "A": assessment, "R": recommendation) for the standardization of patient transfer. This concept was originally developed for high-risk areas with the aim of securing consistent transfer of information. ${ }^{27,28}$

\section{Conclusion}

Both patients reported suspicious clinical findings at an early stage. In patient 1 the postoperative occurrence of 
Table 2 Clinical Tests Depending on the Catheter Position

\begin{tabular}{|c|c|c|c|}
\hline $\begin{array}{l}\text { Catheter } \\
\text { Position }\end{array}$ & $\begin{array}{l}\text { Loss of Resistance to } \\
\text { Saline (LORS) }\end{array}$ & Aspiration Test & Passive Fluid Inflow Test \\
\hline Interligamentary & $\begin{array}{l}\text { LORS possibly occurs when } \\
\text { reaching a larger local } \\
\text { anesthetic depot }\end{array}$ & Negative & No passive inflow \\
\hline Epidural & Yes & $\begin{array}{l}\text { Possibly blood (vascular } \\
\text { puncture) or injected saline } \\
\text { (limited "cold" reflux) }\end{array}$ & Positive \\
\hline Subdural & $\begin{array}{l}\text { LORS occurs when the } \\
\text { epidural space is reached }\end{array}$ & Negative & No passive inflow \\
\hline Spinal & $\begin{array}{l}\text { LORS occurs when the } \\
\text { epidural space is reached }\end{array}$ & $\begin{array}{l}\text { Cerebrospinal fluid (constant } \\
\text { "warm" reflux) }\end{array}$ & $\begin{array}{l}\text { Depends on how far the catheter end is elevated above } \\
\text { the puncture level: passive inflow stops when the catheter } \\
\text { end is lowered }\end{array}$ \\
\hline Pleural & Yes & Negative & Positive \\
\hline
\end{tabular}

increasing numbness of the left leg should have led directly to a stop of the epidural infusion. Within two hours, the symptoms either would have resolved (consequence: continuation of epidural infusion with reduced dose), or otherwise would had given rise to immediate MRI of the thoracic spine (consequence: early laminectomy and evacuation of the epidural hematoma). Case report 2 shows that a carefully administered fractionated test dose with local anesthetic over a prolonged period of time is an important element in detecting "epidural" catheter malposition. Alternative methods that support needle guidance and catheterization like electrical epidural stimulation or epidural waveform analysis should be considered. An SBAR concept should be implemented for the standardization of patient transfer.

\section{Abbreviations}

ASA PS, American Society of Anesthesiologists Physical Status; ASIA, American Spinal Injury Association; ASRA, American Society of Regional Anesthesia; BMI, body mass index; CRP, C-reactive protein; CSF, cerebrospinal fluid; CT, computed tomography; ECG, electrocardiogram; Epidural electrical stimulation; GCS, Glasgow Coma Scale; GFR, glomerular filtration rate; LATD, local anesthetic test dose; LORS; loss of resistance to saline; MRI, magnetic resonance imaging; PACU, post-anesthesia care unit; SOP; standard operating procedure; TEA, thoracic epidural analgesia.

\section{Acknowledgments}

Editorial assistance, in the form of language editing and correction, was provided by XpertScientific Editing and Consulting Services.

\section{Funding}

The authors have not declared a specific grant for this publication from any funding agency.

\section{Disclosure}

The authors report no conflicts of interest in this work.

\section{References}

1. Pöpping DM, Elia N, Van Aken HK, et al. Impact of epidural analgesia on mortality and morbidity after surgery: systematic review and metaanalyses of randomized controlled trials. Ann Surg. 2014;259 (6):1056-1067. doi:10.1097/SLA.000000000000237

2. Cummings KC, Zimmerman NM, Maheshwari K, et al. Epidural compared with non-epidural analgesia and cardiopulmonary complications after colectomy: a retrospective cohort study of 20,880 patients using a national quality database. J Clin Anesth. 2018;47:12-18. doi:10.1016/j.jclinane.2018.03.005

3. Melloul E, Lassen K, Roulin D, et al. Guidelines for perioperative care for pancreatoduodenectomy: enhanced recovery after surgery recommendations 2019. World J Surg. 2020;44:2056-2084.

4. Weiss R, Pöpping DM. Is epidural analgesia still a viable option for enhanced recovery after abdominal surgery? Curr Opin Anaesthesiol. 2018;31:622-629. doi:10.1097/ACO.0000000000000640

5. Børglum J, Gögenur I, Bendtsen F. Abdominal wall blocks in adults. Curr Opin Anaesthesiol. 2016;29:638-643. doi:10.1097/ ACO.0000000000000378

6. Marciniak D, Kelava M, Hargrave J. Fascial plane blocks in thoracic surgery: a new era or plain painful? Curr Opin Anaesthesiol. 2020;33 (1):1-9. doi:10.1097/ACO.0000000000000803 
7. Absalom AR, Martinelli G, Scott NB. Spinal cord injury caused by direct damage by local anaesthetic infiltration needle. Br J Anaesth. 2001;87(3):512-515. doi:10.1093/bja/87.3.512

8. Bromage PR, Benumof JL. Paraplegia following intracord injection during attempted epidural anesthesia under general anesthesia. Reg Anesth Pain Med. 1998;23(1):104-107. doi:10.1097/00115550199823010-00020

9. Cekic G, De Kock M, Kremer Y, et al. Paraplegia after combined general and epidural anesthesia: a case report. Acta Anaesth Belg. 2008;59:95-98.

10. Cook TM, Counsell D, Wildsmith JAW, et al. Major complications of central neuraxial block: report on the Third National Audit Project of the Royal College of Anaesthetists. Br J Anaesth. 2009;102:179-190. doi:10.1093/bja/aen360

11. Kang XH, Bao FP, Xiong XX, et al. Major complications after epidural anesthesia: a prospective study of 5083 cases at a single hospital. Acta Anaesthesiol Scand. 2014;58:858-866. doi:10.1111/ aas. 12360

12. Kao MC, Tsai SK, Tsou MY, et al. Paraplegia after delayed detection of inadvertent spinal cord injury during thoracic epidural catheterization in an anesthetized elderly patient. Anesth Analg. 2004;99:580-583. doi:10.1213/01.ANE.0000130391.62612.3E

13. Katz N, Hurley R. Epidural anesthesia complicated by fluid collection within the spinal cord. Anesth Analg. 1993;77(5):1064-1065. doi:10.1213/00000539-199311000-00033

14. Nagathan DS, Singh BP, Ghatanatti S, et al. Spinal cord injury: a rare complication following thoracic epidural anesthesia for percutaneous nephrolithotomy. Acta Anaesthesiol Taiwan. 2012;50:81-83. doi:10.1016/j.aat.2012.05.001

15. Tripathi M, Nath SS, Gupta RK. Paraplegia after intracord injection during attempted epidural steroid injection in an awake patient. Anesth Analg. 2005;101:1209-1211. doi:10.1213/01. ANE.0000175765.76237.0A

16. Volk T, Wolf A, Van Aken H, et al. Incidence of spinal haematomas after epidural puncture: analysis from the German network for safety in regional anaesthesia. Eur $J$ Anaesthesiol. 2012;29:170-176. doi:10.1097/EJA.0b013e3283504fec

17. Horlocker T, Vandermeulen E, Kopp S, et al. Regional anesthesia in the patient receiving antithrombotic or thrombolytic therapy: American Society of Regional Anesthesia and Pain Medicine evidence-based guidelines (4th edition). Reg Anesth Pain Med. 2018;43:263-309. doi:10.1097/AAP.0000000000000763
18. Vandermeulen E, Van Aken H, Vermylen J. Anticoagulants and spinal-epidural anesthesia. Anesth Analg. 1994;79(6):1165-1177. doi:10.1213/00000539-199412000-00024

19. Guay J. The epidural test dose: a review. Anesth Analg. 2006;102 (3):921-929. doi:10.1213/01.ane.0000196687.88590.6b

20. Balki M, Malavade A, Ye XY, et al. Epidural electrical stimulation test versus local anesthetic test dose for thoracic epidural catheter placement: a prospective observational study. Can J Anaesth. 2019;66:380-387. doi:10.1007/s12630-019-01301-2

21. Kwofie MK, Launcelott G, Tsui BCH. Determination of thoracic epidural catheter placement: electrical epidural stimulation (Tsui test) is simple, effective, and underutilized. Can $J$ Anaesth. 2019;66:360-364. doi:10.1007/s12630-019-01302-1

22. Lirk P, Colvin J, Steger B, et al. Incidence of lower thoracic ligamentum flavum midline gaps. Br J Anaesth. 2005;94:852-855. doi:10.1093/bja/aei133

23. Hardy PAJ. Can epidural catheters penetrate dura mater? An anatomical study. Anaesthesia. 1986;41(11):1146-1147. doi:10.1111/ j.1365-2044.1986.tb12968.x

24. Lubenow $\mathrm{T}$, Keh-Wong $\mathrm{E}$, Kristof $\mathrm{K}$, et al. Inadvertent subdural injection: a complication of an epidural block. Anesth Analg. 1988;67(2):175-179. doi:10.1213/00000539-198802000-00012

25. Wills JH. Rapid onset of massive subdural anesthesia. Reg Anesth Pain Med. 2005;30(3):299-302. doi:10.1016/j.rapm.2005.01.002

26. Slavin KV. Intramedullary placement of intrathecal catheter: report of a rare complication of intrathecal therapy. Neuromodulation. 2006;9:94-99. doi:10.1111/j.1525-1403.2006.00048.x

27. Randmaa M, Martensson G, Swenne CL, et al. SBAR improves communication and safety climate and decreases incident reports due to communication errors in an anesthetic clinic: a prospective intervention study. BMJ Open. 2014;4:1-8. doi:10.1136/bmjopen2013-004268

28. Von Dossow V, Zwissler B. Recommendations of the German Society of Anesthesiology and Intensive Care Medicine on structured patient handover in the perioperative phase: SBAR concept. Anaesthesist. 2016;65:148-150. doi:10.1007/s00101-015-0126-3
Local and Regional Anesthesia

\section{Publish your work in this journal}

Local and Regional Anesthesia is an international, peer-reviewed, open access journal publishing on the development, pharmacology, delivery and targeting and clinical use of local and regional anesthetics and analgesics. The journal welcomes submitted papers covering original research, basic science, clinical studies, reviews \& evaluations, guidelines, expert opinion and commentary, case reports and extended reports. The manuscript management system is completely online and includes a very quick and fair peer-review system, which is all easy to use. Visit http://www.dovepress.com/testimonials. php to read real quotes from published authors. 